\title{
Application Research of Off-grid Home Photovoltaic Pow- er System in Shaanxi Northern Region
}

\author{
Ke Cheng ${ }^{1}$, Liu Hao ${ }^{2}$, Jie Yang ${ }^{1}$ \\ ${ }^{1}$ School of Power and Energy, Northwestern Polytechnical University, Xi'an, China \\ ${ }^{2}$ Shaanxi Regional Electric Power Group Co., LTD., Xi'an, China \\ Email: cksolar@sohu.com
}

Received February, 2013

\begin{abstract}
Because working performance of off-grid home photovoltaic power system is influenced by factors of solar radiation, ambient temperature and installation angle, this research established power supply model, analyzed working performance and optimized system configuration, by referencing weather conditions of Yulin and Yan'an and those factors. Results showed that under given solar radiation and ambient temperature, difference of installation angle can cause 30\% to $40 \%$ difference of performance. In order to meet power demand, installation angles of Yulin and Yan'an were selected as 40 degree and 30 degree, and annual output power were $1.44 \mathrm{kWh} / \mathrm{Wp}$ and $1.32 \mathrm{kWh} / \mathrm{Wp}$. Based on those results, the configuration of Yulin and Yan'an was $150 \mathrm{Wp}$ and $170 \mathrm{Wp}$, and annual output power was $172.70 \mathrm{kWh}$ and $179.66 \mathrm{kWh}$. Systems optimized above can meet the mid-scale demand in Shaanxi northern region and build theoretical foundation of application.
\end{abstract}

Keywords: Off-grid Home Photovoltaic Power System; Photovoltaic; Solar

\section{Introduction}

Shaanxi northern region is located in the north of Shaanxi province, including Yulin and Yan'an, belonging to semi-arid monsoon climate zone. With sufficient sunshine, the mean sunshine hours are 6-8 hours a day, $2600-2900$ hours a year and the solar global radiation is $5000-5500 \mathrm{MJ} / \mathrm{m}^{2}$. These areas have favorable conditions of developing and utilizing solar energy. By the influence of Maowusu desert and Loess plateau, some residents in this area live in the scattered and outfield, so electricity is unavailable for them because the difficulty of power grid extension, off-grid home photovoltaic power system provide them an effective way to solve those problems.

Off-grid home photovoltaic power system consists of PV modules, batteries, controllers and inverters. As power generation equipment, the performance of PV modules is greatly influenced by environmental factors[1-2]. In order to give full play to the performance of the system, this research established power supply model, analyzed working performance and optimized system configuration, which laid a theoretical foundation for the application of off-grid home photovoltaic power system in these areas by referencing weather conditions of Yulin and Yan'an as well as other factors such as solar radiation, ambient temperature and installation angle.

\section{Electricity Load}

Dispersed rural households can generally be divided into low, mid-scale and high levers according to their electricity consumption level. The low levers primarily use light, the mid-scale levels add TV and the high levels add washing machines and refrigerators. The purpose of this research is to meet the demand of mid-level peasant households according to actual electricity price and photovoltaic power generation cost. The electricity consumption has list in Table 1.

According to the table above, the peak power of midlevel rural household is $101.6 \mathrm{~W}$, daily electricity consumption is $0.428 \mathrm{kWh}$, annual electricity consumption is $156.2 \mathrm{kWh}$.

\section{Weather Conditions}

Shaanxi northern region has the most abundant solar energy resources in Shaanxi province, including Yulin a

Table 1. Electrical load of rural household.

\begin{tabular}{cccccc}
\hline Appliances & Number & Power & $\begin{array}{c}\text { Working } \\
\text { hours }\end{array}$ & $\begin{array}{c}\text { Synchronization } \\
\text { Coefficient }\end{array}$ & $\begin{array}{c}\text { Peak } \\
\text { Power }\end{array}$ \\
\hline CFL & 3 & 9 & 5 & 0.8 & 21.6 \\
TV & 1 & 70 & 4 & 1 & 70 \\
$\begin{array}{c}\text { Satellite } \\
\text { receiver }\end{array}$ & 1 & 10 & 4 & 1 & 10 \\
\hline
\end{tabular}


Yan'an. Yulin is located in the northern of Shaanxi province and situated from $107^{\circ} 28^{\prime}-111^{\circ} 15^{\prime} \mathrm{E}$ longitude to $36^{\circ} 57^{\prime}-39^{\circ} 34^{\prime} \mathrm{N}$ latitude, with the annual average temperature is $10^{\circ} \mathrm{C}$ and average sunshine hours are from 2500 to 2900 hours. Yan'an is situated from $107^{\circ} 41$ '- $110^{\circ} 31^{\prime} \mathrm{E}$ longitude to $35^{\circ} 21^{\prime}-37^{\circ} 31^{\prime} \mathrm{N}$ latitude , connected with the southern part of Yan'an. Its annual average temperature is $11^{\circ} \mathrm{C}$ and average sunshine hours are from 2300 to 2700 hours[3]. Their sunshine radiation and average temperature in every month are showed in Figures 1 and 2.

\section{Performance Prediction}

\subsection{Theory Model}

According to the working principle of photovoltaic cells, the factors effect working efficiency of photovoltaic cell, and in accordance with the characteristics of semiconductor PN junction[4-5], relationship between photovoltaic battery output current and output voltage can be showed use the follow equation:

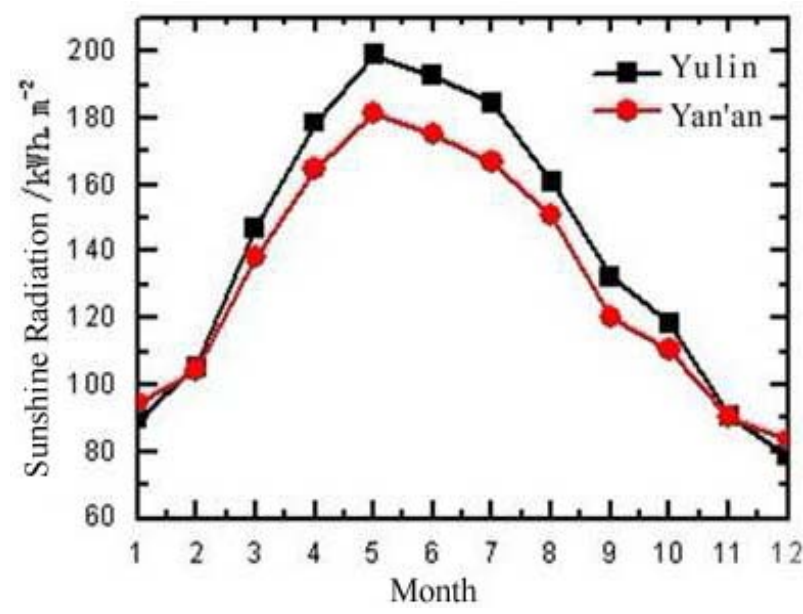

Figure 1. Monthly averaged solar radiation incident.

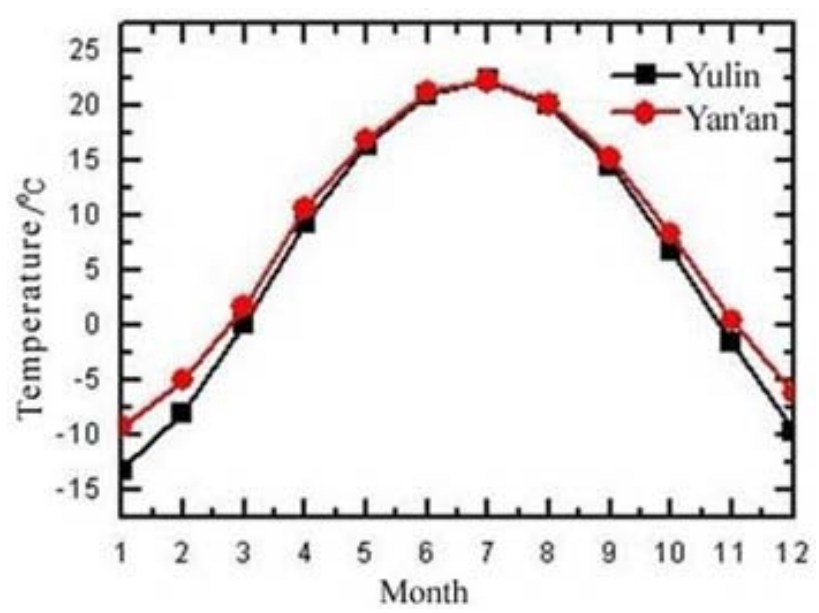

Figure 2. Monthly averaged solar radiation incident.

$$
\begin{aligned}
I= & I_{p h}-I_{s a t}\left\{\exp \left[\frac{q\left(V+R_{s} I\right)}{n K T}\right]-1\right\} \\
& -\frac{V+R_{s} I}{R_{s h}}
\end{aligned}
$$

Among it :

$I$ - output current of photovoltaic panels(A)

$V$-output voltage of photovoltaic panels(V)

$q$ - charge quantity an electronic contains $\left(1.6 \times 10^{-19} \mathrm{C}\right)$

$K$-disposal of Boltzmann ' s constant $\left(1.38 \times 10^{-23} \mathrm{~J} / \mathrm{K}\right)$

$T$ - surface temperature of photovoltaic panels(K)

$n$-ideal factor of photovoltaic panels $(\mathrm{n}=1.5)$

$I_{\text {sat }}$-reverse saturation current of photovoltaic panels, can be expressed as follows:

$$
I_{\text {sat }}=I_{r r}\left[\frac{T}{T_{r}}\right]^{3} \cdot \exp \left[\frac{q E_{\text {gap }}}{k A}\left(\frac{1}{T_{r}}-\frac{1}{T}\right)\right]
$$

Among it:

$T_{r}$-reference temperature of the photovoltaic panels

$I_{r r}$-reverse saturation current when photovoltaic cell work in temperature boundary $T_{r}(0 \mathrm{k})$

$E_{g a p}$-required energy when semiconductor materials across the clearance

From formula (2) we can see reverse saturation current $I_{\text {sat }}$ is the function of temperature $T$. Secondly, $I_{p h}$, produced by photovoltaic panels, is change by the change of sunshine intensity and atmospheric temperature. The relationship between them is:

$$
I_{p h}=\left[I_{s c r}-\frac{K_{i}}{1000}\left(T-T_{r}\right)\right] \times s_{i}
$$

Among it:

$I_{\text {scr }}$-the measured short circuit current value when photovoltaic cell work in the reference temperature and sunlight condition is $1 \mathrm{~kW} / \mathrm{m}^{2}$

$K_{l}$-temperature coefficient of photovoltaic panel's short circuit current $(\mathrm{mA} / \mathrm{K})$

$$
s_{i} \text { - sunshine intensity }\left(\mathrm{kW} / \mathrm{m}^{2}\right)
$$

The output power $\mathrm{P}$ is the product of current I and voltage $V$. The relation can be showed use formula (4):

$$
\begin{aligned}
P= & V I=V I_{p h} \\
& -V I_{s a t}\left\{\exp \left[\frac{q\left(V+R_{s} I\right)}{n K T}\right]-1\right\} \\
& -\frac{V+R_{s} I}{R_{s h}} V
\end{aligned}
$$

We can see sunshine intensity and atmospheric temperature can affect the performance of photovoltaic cell.

\subsection{Performance Simulation}

In light of the theory above, we arrange PV modules toward south, monthly simulate and calculate the electricity generation performance of $1 \mathrm{Wp}$ PV modules on dif- 
ferent installation angle, based on the date of local solar radiation and the average temperature every month. The results have showed in Figures 3 and $\mathbf{4}$ :

We can come to the conclusion that $10^{\circ}$ installation angle of photovoltaic module can obtain the maximum monthly output power in May in Shaanxi northern region, which Yulin is $0.15 \mathrm{kWh} / \mathrm{Wp}$, Yan'an is $0.13 \mathrm{kWh} / \mathrm{Wp}$. It is because in May the local sunshine radiation reach the highest lever throughout the year. At the same time, the temperature is not high and temperature influence is not big.

\subsection{Configuration Optimization}

According to the results of performance simulation, we can get the electricity generation performance of PV modules in different installation angles, as showed in Figure 5:

We can find that the maximum annual output power occurs when the installation angle is $40^{\circ}$ in Yulin and $30^{\circ}$ in Yan'an, and they are $1.44 \mathrm{kWh} / \mathrm{Wp}$ and $1.32 \mathrm{kWh} / \mathrm{Wp}$. In both cities we can get the minimum output power when the installation angle is $90^{\circ}$, and they are $0.96 \mathrm{kWh} / \mathrm{Wp}$ and $0.84 \mathrm{kWh} / \mathrm{Wp}$.

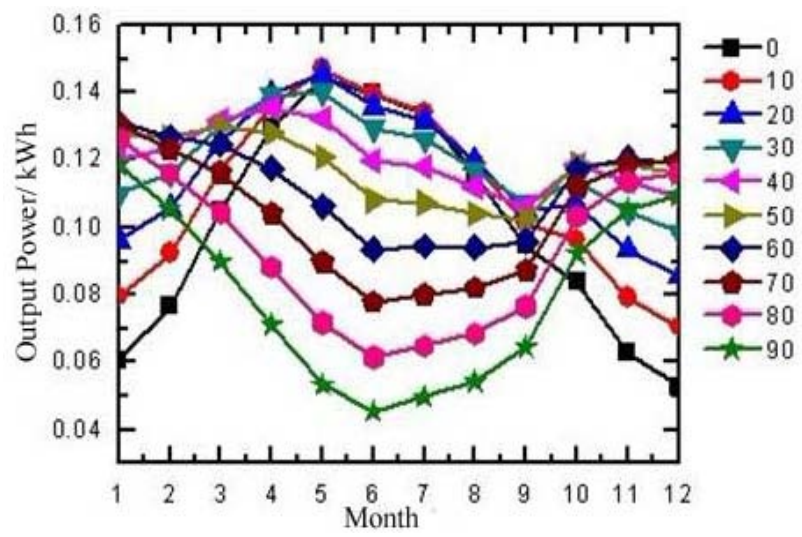

Figure 3. Monthly averaged output power of Yulin.

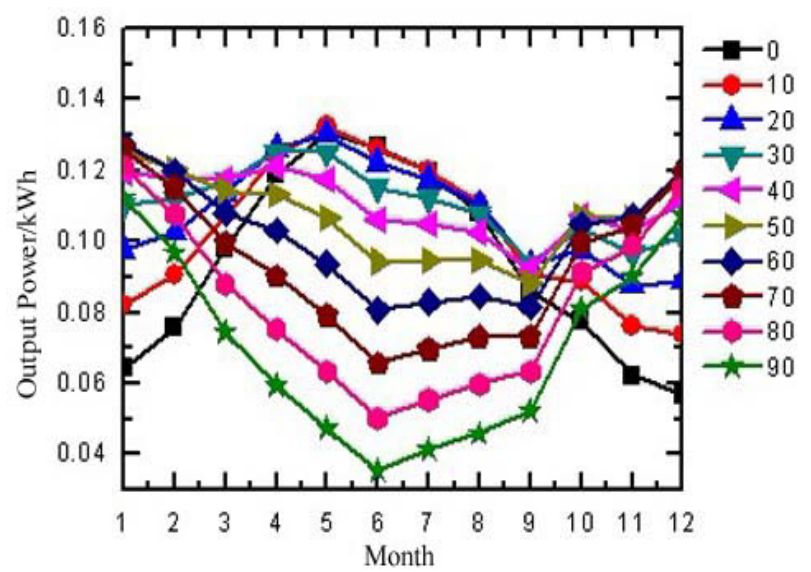

Figure 4. Monthly averaged output power of Yan'an.
The designed target of the off-grid photovoltaic power system is to balance the average power generation in each month and meet the electricity demand when the output power reach minimum lever. In another word, we don't see the annual power output or total power output as the highest goal. It is more incline to calculate the worst case and part of sunshine may be abandoned in the month which sunshine is sufficient. Therefore, it is necessary to further analysis minimum output power in different installation angle, the result is show in Figure 6:

Compare the minimum monthly output power in all installation angles, in Yulin it can reach the maximum $0.11 \mathrm{kWh} / \mathrm{Wp}$ when the installation angle is $40^{\circ}$ and in Yan'an it can reach the maximum $0.09 \mathrm{kWh} / \mathrm{Wp}$ when the installation angle is $30^{\circ}$. So according to the installation angles above, assumes that the charge and discharge loss is $20 \%$ and consider the battery energy storage need in three days, as well as the controller, inverter safety margin, the basic configuration is as follows:

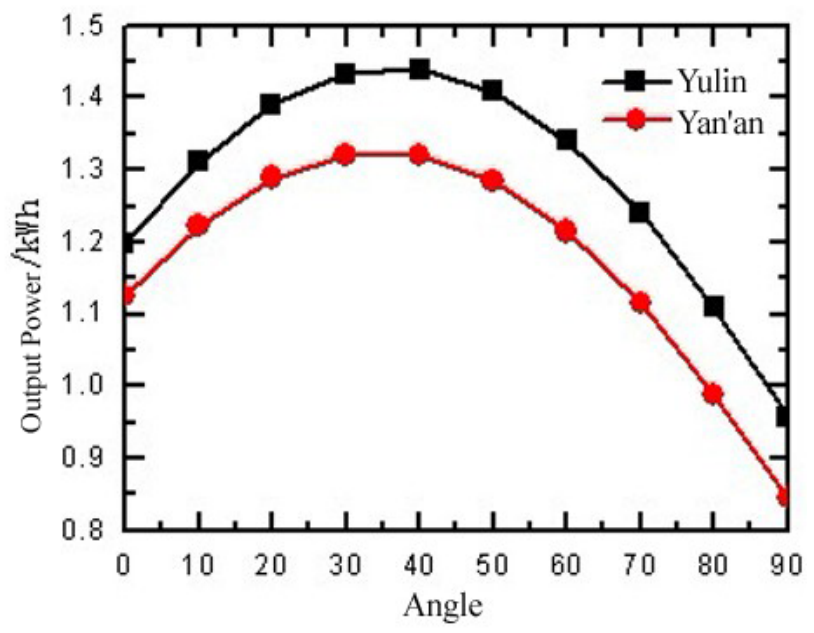

Figure 5. Yearly output power under different installation angle.

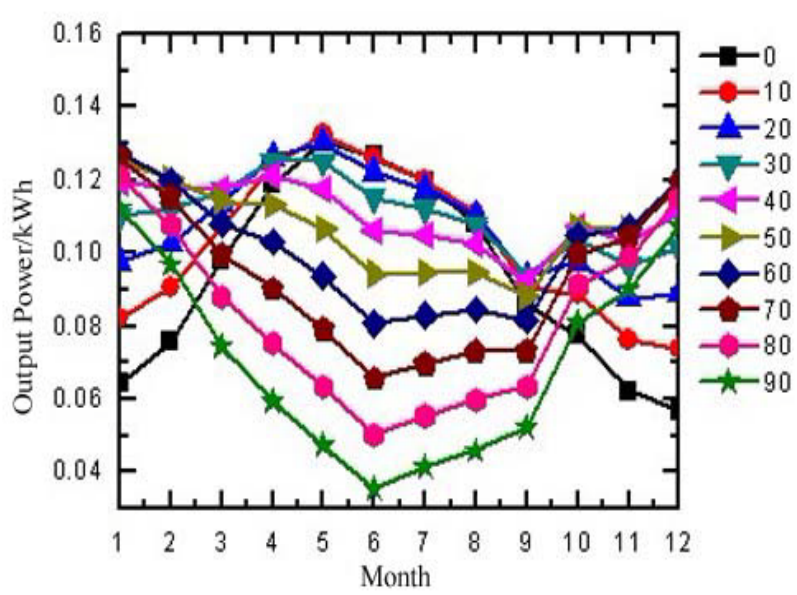

Figure 6. Minimize monthly averaged output power of different installation angle. 
According to the configuration, the output power capacity of the off-grid home photovoltaic power system is $172.70 \mathrm{kWh}$ in Yulin, $179.66 \mathrm{kWh}$ in Yan'an, more than the mid-scale farmers' annual electricity consumption, can solve their problems of use electricity.

\section{Conclusions}

This research studied the off-grid home photovoltaic power system in Shaanxi northern region according to the meteorological data, the establishment of performance model, and gets the following conclusions:

1) In the same area, solar radiation and ambient temperature are certain, but we can choose the best installation angle, different installation angle can lead to $30 \%$ $40 \%$ gap of the performance in the system.

2) Off-grid home photovoltaic power system should meet the demand of electricity consumption when the output power reaches minimum. In light of this principle, the installation angle should be $40^{\circ}$ in Yulin and $30^{\circ}$ in Yan'an.

3) According to the installation angle above, the power generation of PV modules can reach $1.44 \mathrm{kWh} / \mathrm{Wp}$ in
Yulin and $1.32 \mathrm{kWh} / \mathrm{Wp}$ in Yan'an, so the annual power output of $150 \mathrm{Wp}$ and $170 \mathrm{Wp}$ systems is $172.70 \mathrm{kWh}$ and $179.66 \mathrm{kWh}$, which can meet the electricity demand in mid-scale rural families.

The off-grid home photovoltaic power system has been widely used in Shaanxi northern region, we will optimize the system further with considering the actual situation, such as wind, snow, dirt and other factors.

\section{REFERENCES}

[1] H. Sheng and Z. Q. Zeng, "Solar photovoltaic technology,” Beijing: Chemical Industry Press, 2005.

[2] A. Li, "Solar Photovoltaic Systems Engineering," Beijing: Beijing Industrial University Press, 2001.

[3] B. Z. Wang, "Calculation of solar radiation of the slope ground Solar Energy,” Vol. 3, 2000, pp. 16-17

[4] J. Q. Wang, "Stand-alone Photovoltaic Power System Power Electronics Technology,” Vol. 3, 2009, pp. 53-47.

[5] W. T. Li, "Analysis and Calculation of the Best Angle of Photovoltaic Array of Village without Electricity in Qinghai Province,” Qinghai Technology, Vol. 4, 2003, pp. 35-37. 